\title{
0 equilíbrio de Nash como uma solução para o conflito entre eficiência e custo na escolha de sistemas de tratamento de esgoto sanitário com 0 auxílio de um modelo de tomada de decisão
}

The Nash equilibrium as a solution to the conflict between efficiency and cost in the
choice of systems for sanitary sewage treatment using a decision making model

\begin{abstract}
Alexandre Bevilacqua Leoneti
Mestre em Administração de Organizações pela Faculdade de Economia, Administração e Contabilidade de Ribeirão Preto da Universidade de São Paulo
\end{abstract} (FEARP/USP)

\section{Sonia Valle Walter Borges de Oliveira}

Doutora em Administração de Empresas pela Faculdade de Economia, Administração e Contabilidade da Universidade de São Paulo (FEA/USP). Professora doutora da FEARP/USP

\section{Marcio Mattos Borges de Oliveira}

Doutor em Engenharia Mecânica pela Escola de Engenharia de São Carlos (EESC/USP). Professor-associado da FEARP/USP

\begin{abstract}
Resumo
A escolha de estações de tratamento de esgoto pode, dentre outras coisas, envolver um conflito entre a eficiência e o custo, pois para o menor custo possível esta escolha também deverá satisfazer várias exigências ambientais. Para auxiliar na escolha de uma estação de menor custo, um modelo baseado em técnicas de tomada de decisão foi desenvolvido por Oliveira (2004). Todavia, se não forem levados em consideração os outros critérios envolvidos, a interação entre os tomadores de decisão e suas respectivas estratégias podem fazer com que a escolha do sistema de tratamento não seja a mais adequada. Para estes casos, o equilíbrio de Nash pode oferece uma solução, construída com base na interação entre os jogadores, a qual poderia satisfazer razoavelmente os interesses conflitantes. Desta forma, o objetivo desta pesquisa foi, com base nos dados de saída do modelo de Oliveira (2004), encontrar o equilíbrio de Nash para propor uma solução para o conflito entre a eficiência e o custo nas escolhas do sistema de tratamento de esgoto sanitário. A comparação entre os diferentes resultados alcançados, quando apenas considerado o critério de menor custo ou de maior eficiência, demonstrou que a adoção do equilíbrio de Nash pode ser uma alternativa viável para solucionar o conflito entre a eficiência e o custo nas escolhas das estações de tratamento de esgoto sanitário.
\end{abstract}

Palavras-chave: equilíbrio de Nash, tomada de decisão, tratamento de esgoto.

\begin{abstract}
The choice of sewage treatment plants may, among others, involve a conflict between efficiency and cost, because for the lowest possible cost, this choice should meet some environmental requirements. To assist in the choice of a treatment system for municipal sanitary sewer, a model based on techniques of decision making was developed by Oliveira (2004). However, if the other criteria involved are not considered, the interaction between decision makers and their strategies can turn the choice of the treatment system into an inadequate one. For these cases, the Nash equilibrium may offer a solution based on the interaction between players, which could reasonably satisfy the conflicting interests. Thus, the main objective of this research was, based on the data output of Oliveira's model, to find the Nash equilibrium to propose a solution to the conflict between efficiency and cost in the choice of a system for the sewage treatment. The different results found, when taken into account only the criterion of lower cost and the criteria of lowest cost and efficiency, demonstrated that the Nash equilibrium adoption can be a viable alternative to solve the conflict between efficiency and cost in the choice of treatment plants for sewage.
\end{abstract}

Keywords: Nash equilibrium, decision making, sewage treatment. 


\section{Introdução}

O esgoto sanitário é ainda um dos principais problemas na preservação das águas no Brasil. Em grande parte do país o esgoto ainda é lançado diretamente nos corpos de água, gerando problemas de poluição e até de contaminação, devido à presença de compostos tóxicos e/ou organismos patogênicos.

No ano de 2000, de acordo com a Pesquisa Nacional de Saneamento Básico (IBGE, 2000), no Brasil, quase todo o esgoto sanitário coletado nas cidades ainda era despejado in natura em corpos de água ou no solo, sendo apenas tratado em 20,2\% dos municípios. Segundo dados do Sistema Nacional de Informações em Saneamento (SNIS, 2007), em 2006, esta situação pouco se alterou. Apesar do índice médio de atendimento urbano para o abastecimento de água mostrar um valor relativamente elevado, em torno de 93,1\%, o índice médio de coleta de esgoto sanitário ainda era muito baixo, tendo um índice médio nacional de 48,3\%, sendo tratados apenas 32,2\% deste esgoto.

Uma solução para a preservação das águas é o investimento em saneamento e no tratamento do esgoto sanitário coletado. No entanto, a escolha de um sistema de tratamento de esgoto sanitário a ser instalado em um município deve levar em consideração, além da adequação técnica do projeto e da aplicação adequada dos recursos financeiros, a eficiência de remoção de poluentes e matéria orgânica, uma vez que deverá atender aos requisitos ambientais do local a ser implantado.

No processo de tomada de decisão, dentre os critérios frequentemente avaliados, tais como: eficiência de remoção, necessidade de área, simplicidade do processo, custo econômico etc., os engenheiros e técnicos responsáveis pelos projetos de estação de tratamento de esgoto podem divergir entre várias estratégias. Por exemplo, eles podem adotar sistemas que minimizem o custo total, compreendendo a implantação, operação e manutenção do mesmo, ou podem adotar sistemas que minimizem os impactos ambientais. Todavia, se não forem levados em consideração os vários critérios envolvidos, a interação entre esses tomadores de decisão e suas respectivas estratégias pode fazer com que a escolha do sistema de tratamento não seja a mais adequada.

A interação entre tomadores de decisão é como um jogo de estratégias, no qual seus participantes são reconhecidos como jogadores (OSBORNE, 2004).

Um jogo envolve uma interdependência mútua das ações dos seus jogadores, e isso leva naturalmente os jogadores a considerarem, em suas decisões, os efeitos sobre os demais jogadores, assim como as reações destes. (FIANI, 2006, p. 14).

Por meio da utilização da teoria dos jogos, torna-se possível entender melhor a situação de conflito e encontrar resultados possíveis para os jogos de estratégias (SHIMIZU, 2006). Quando o resultado encontrado for a melhor resposta possível de cada jogador às estratégias dos demais, considera-se que foi encontrado o equilíbrio de Nash para o jogo (BIERMAN; FERNANDEZ, 1998).

Este equilíbrio, proposto por Nash (1951), pode não apresentar respostas sob uma forma maximizada ou minimizada, mas pode representar os diversos interesses envolvidos. Por exemplo, na escolha de um sistema de tratamento de esgoto, um hipotético jogador chamado "econômico" optaria por um sistema de menor custo, enquanto um outro hipotético jogador chamado "ecológico" optaria por um sistema mais eficiente. Se for considerada somente a opinião de um desses jogadores, haveria uma decisão do tipo: (a) mais barata possível, mas não tão eficiente ao ponto de satisfazer às restrições legais, ou (b) mais eficiente possível, mas não tão acessível à determinada realidade financeira. A maximização ou a minimização da resposta de um determinado problema proporcionaria soluções deste tipo. Todavia, o equilíbrio de Nash propõe uma solução que é construída com base na interação entre os jogadores, o que poderia satisfazer razoavelmente os interesses conflitantes.

Para encontrar os resultados dos jogos de estratégia e eventualmente os seus equilíbrios de Nash, é necessário realizar a modelagem destes jogos.

Ao modelar um jogo, o que se está fazendo é representar uma situação de interação estratégica de forma abstrata, isto é, focalizando-se apenas aqueles elementos considerados mais importantes para explicar como os jogadores interagem entre si. (FIANI, 2006, p. 43).

Para isto, devem ser levantados os resultados factíveis, que são derivados das interações estratégicas entre os jogadores e incorporálos, sinteticamente, em uma tabela de pagamentos, na qual estará explícito o que cada jogador receberá quando ele adotar determinada estratégia em oposição àquelas de seus competidores. Esta tabela é também conhecida como matriz e tem o objetivo de representar os resultados das combinações de estratégias escolhidas para cada jogador (VARIAN, 2003).

No contexto deste trabalho, o nome mais apropriado para a tabela de pagamentos seria tabela de custo e eficiência, pois representaria os custos e os índices de eficiência para os jogadores "econômico" e "ecológico", respectivamente. Esta tabela poderia receber valores sob a forma monetária para representar as opções do jogador "econômico", e sob a forma de um índice de eficiência, indicando a quantidade de DBO no efluente final, para representar as opções do jogador "ecológico". Por exemplo, para uma determinada combinação de estratégias, o valor para o jogador "econômico" poderia ser R\$1,3 milhão, enquanto que para o ecológico poderia ser $13 \mathrm{mg} / \mathrm{L}$ de $\mathrm{DBO}$. Se estes valores fossem maiores dos que os 
encontrados em outra combinação de estratégia, essa combinação seria preterida, pois os jogadores visam pagar menos e possuir um efluente com menor DBO.

No processo gerencial, modelos de tomada de decisão são cada vez mais utilizados por tomadores de decisão, pois permitem simular diversos cenários possíveis e estudar mais profundamente um problema e/ou oportunidade (LACHTERMACHER, 2004). Segundo Massukado e Zanta (2006, p. 134), "a utilização de cenários torna-se um importante instrumento de gestão para auxiliar nas tomadas de decisão".

Um modelo de tomada de decisão desenvolvido por Oliveira (2004) utiliza as técnicas de análise de sensibilidade e a árvore de decisão quantitativa para auxiliar na escolha de um sistema de tratamento de esgoto sanitário para municípios. Este modelo é composto por planilhas de cálculo de oito sistemas de tratamento, as quais são compostas por itens de implantação, operação e manutenção, e os seus dados de saída são: o custo total do sistema, em dólares, e a sua eficiência, como estimativa da DBO em seu efluente final.

O objetivo principal desta pesquisa foi, por meio da simulação de uma versão mais atualizada do modelo de Oliveira (2004), compor a tabela de custo e eficiência dos jogadores "econômico" e "ecológico", e encontrar o equilíbrio de Nash para propor uma solução alternativa à de menor custo econômico que o modelo propõe. Também procurouse verificar a divergência nas soluções propostas quando considerado somente o custo total do sistema e quando considerado o conflito entre a eficiência de remoção e o custo total do sistema, sendo a demanda bioquímica de oxigênio (DBO), no efluente final, o único impacto ambiental considerado. Esta nova abordagem visa aumentar a possibilidade de solucionar o conflito entre eficiência e custo nas escolhas das estações de tratamento de esgoto sanitário.

Os objetivos específicos foram: (a) fazer a simulação do modelo de Oliveira (2004) com o auxílio do software Crystal Ball ${ }^{\circledR}$; (b) criar, a partir dos dados de saída do modelo, a tabela de custo e eficiência para os jogadores "econômico" e "ecológico" em cada iteração da simulação; (c) encontrar o equilíbrio de Nash na tabela criada; e (d) comparar a escolha de menor custo do modelo com o equilíbrio de Nash encontrado em cada iteração da simulação.

\section{Referencial teórico}

\section{Modelos de tomada de decisão}

Imagina-se com frequência que modelos são constituídos apenas em termos de equações matemáticas. Todavia, modelos são definidos como representações imperfeitas e abstratas de estruturas e funções do mundo real (ODUM, 1971, p. 277). Um modelo pode descrever, representar e imitar procedimentos, "estabelecendo o relacionamento das variáveis com os objetivos, da melhor maneira possível, obedecendo à limitação de tempo e de custo" (SHIMIZU, 2006, p. 41).

Existem, basicamente, três tipos de modelos: os físicos, os análogos e os matemáticos ou simbólicos, sendo estes os mais utilizados na modelagem de situações gerenciais. Modelos nos quais alguma das "variáveis representa uma decisão gerencial a ser tomada denominam-se "modelos de decisão"' (LACHTERMACHER, 2004, p. 6).

Alguns pacotes de software de planilhas, como o Excel, podem ser utilizados para a modelagem de problemas de gestão, pois permitem a inserção de todas as fórmulas e relações existentes entre as variáveis. Hillier e Lieberman (2006, p. 64) afirmam que "grande parte do poder das planilhas reside em sua habilidade de revelar imediatamente os resultados de quaisquer alterações feitas na solução".

\section{Modelos de tomada de decisão aplicados ao tratamento de esgoto}

Devido à complexidade que envolve a escolha de um sistema de tratamento de esgoto sanitário, estudos acadêmicos têm demonstrado a necessidade do uso de técnicas adequadas para a avaliação do sistema a ser instalado em um município. Técnicas de tomada de decisão são utilizadas nos modelos desenvolvidos nesses trabalhos, que são criados principalmente por meio de métodos quantitativos.

Segundo Souza (1998), o primeiro estudo sobre técnicas para a análise de sistemas de tratamento de esgotos foi desenvolvido por Lynn, Logan e Charnes, em 1962, quando utilizaram conceitos de análise de sistemas para avaliar a decisão. Após este, vários outros trabalhos foram realizados envolvendo otimização, com o auxílio de métodos clássicos como programação linear, programação dinâmica, programação geométrica, entre outros. Ainda segundo Souza (1998), no início da década de 1970, a Divisão de Engenharia do Exército - U.S. Army Corps of Engineers (COE) - e a Agência de Proteção Ambiental - Environment Protection Agency (EPA), dos Estados Unidos, produziram o primeiro modelo de auxílio à tomada de decisão aplicado ao tratamento de águas residuárias, o modelo CAPDET. Nesta mesma época, a Agência Americana para Desenvolvimento Internacional - U.S. Agency for International Development (USAID) e a Universidade de Oklahoma produziram um modelo de seleção de tecnologias para tratamento de água e saneamento em países em desenvolvimento.

Atualmente, existem alguns modelos que podem ser utilizados gratuitamente para auxiliar na escolha de sistemas de tratamento, como o Sistema de Apoio à Decisão (SAD- PROSAB) (CHERNICHARO et al, 2001), o SANEX ${ }^{\mathrm{TM}}$ (LOETSCHER, 2003) e o Water and Wastewater Treatment Technologies Appropriate for Reuse - WAWTTAR (MCGAHEY, 2003). 
Porém, esses modelos são limitados, pois têm "especificidade para determinadas situações ou condições, nem sempre condizentes para o tratamento de esgoto sanitário municipal" (OLIVEIRA, 2004, p. 51). Além disso, a maioria desses modelos avalia apenas um critério dos vários envolvidos na escolha de um sistema de tratamento de esgoto. Por exemplo, os critérios econômicos são empregados desde os primeiros anos da engenharia sanitária para a avaliação de projetos, e apenas recentemente a consideração de forma conjunta de mais de um critério recebeu atenção.

No Brasil, dentre as publicações disponíveis, foi encontrado apenas um trabalho que trata desse assunto. Miranda e Teixeira (2004) publicaram uma proposta de instrumentos de monitoramento e indicadores de sustentabilidade para aplicação em sistemas urbanos de abastecimento de água e esgotamento sanitário. O procedimento proposto pelos autores foi aplicado à cidade de Jaboticabal, em São Paulo, com ênfase ao sistema de abastecimento de água, sem que houvesse, no entanto, um estudo específico da sustentabilidade da estação de tratamento de esgoto.

Assim, diversos autores propõem que os indicadores fragmentados sejam integrados em um único índice global de sustentabilidade por meio de uma metodologia multicritérios de suporte de decisão. Todavia, a abordagem multicriterial de um problema, inevitavelmente, exigirá a solução de conflitos, que surgem devido às diferentes exigências de cada critério. Por exemplo, em estações de tratamento de esgoto, atender aos critérios econômicos e ambientais significa escolher um sistema de menor custo possível, considerando a eficiência requerida legalmente. As técnicas de negociação em grupos e o equilíbrio de Nash (1951) poderiam ser aplicados para propor uma solução para os mesmos.

Segundo Shimizu (2004, p. 64) "não existe uma solução ótima que satisfaça plenamente a todos os objetivos ou critérios considerados". No entanto, o entrelaçamento de diversos critérios, sendo tratados sob diferentes enfoques, poderá contribuir para o aprimoramento

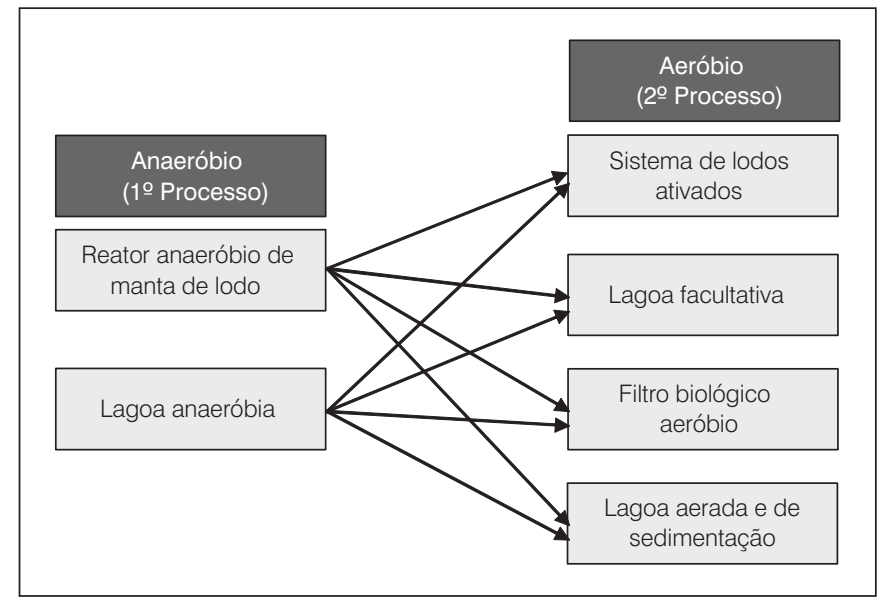

Figura 1 - Processos de tratamento de esgotos empregados no modelo de Oliveira (2004) das decisões no setor de saneamento no Brasil, refletindo, assim, na qualidade de vida da população.

No desenvolvimento desta pesquisa foi utilizada uma versão mais atualizada do modelo de tomada de decisão matemático para a escolha do sistema de tratamento de esgoto proposto por Oliveira (2004), com as adaptações realizadas nos trabalhos preliminares de Leoneti (2009). Esse modelo foi elaborado em Excel e possui oito planilhas que representam a combinação dos seis sistemas de tratamento de esgoto considerados, dois anaeróbios no primeiro processo, seguidos de quatro aeróbios no segundo processo (Figura 1). Estas planilhas foram nomeadas de "A" a "H" (Quadro 1) e podem calcular os custos dos itens de implantação, operação e manutenção dos dois processos do sistema.

De forma isolada, o modelo de Oliveira (2004) considera alguns dos sistemas mais utilizados no Brasil. Todavia, quando considerados em conjunto, o "Sistemas E" (lagoa anaeróbia seguida de lodo ativado) e o "Sistema G" (lagoa anaeróbia seguida de filtro biológico) não são usuais, ou seja, não são adotados como sistema de tratamento de esgoto nos municípios. Além disto, existem outras configurações de sistemas de tratamento de esgoto que não foram consideradas nesta pesquisa, tendo em vista a limitação do modelo de Oliveira (2004) às oito alternativas.

Cada uma das oito planilhas também faz o dimensionamento do primeiro processo (anaeróbio), seguido do dimensionamento do segundo (aeróbio), bem como faz uma estimativa da DBO no efluente final, que pode ser considerado um índice de eficiência. Em uma planilha geral, que é compartilhada por todas as outras, é possível inserir os parâmetros dos municípios para que o custo total do sistema e sua eficiência sejam calculados. Os parâmetros de entrada do modelo de Oliveira (2004) são: (a) população estimada; (b) vazão afluente média; (c) vazão afluente máxima; (d) DBO média afluente; (e) alcance do projeto; (f) classificação do rio receptor; e (g) temperatura média no mês mais frio.

Quadro 1 - Sistemas de tratamento considerados no modelo de Oliveira (2004)

\begin{tabular}{|c|c|c|}
\hline \multirow[b]{2}{*}{$\begin{array}{l}\text { Sistemas } \\
\text { do modelo }\end{array}$} & \multicolumn{2}{|c|}{ Composição dos sistemas } \\
\hline & $\begin{array}{l}\text { Unidade anaeróbia ( } 1^{\circ} \\
\text { processo) }\end{array}$ & $\begin{array}{c}\text { Unidade aeróbia }\left(2^{\circ}\right. \\
\text { processo) }\end{array}$ \\
\hline Sistema A & $\begin{array}{l}\text { Reator anaeróbio de manta } \\
\text { de lodo }\end{array}$ & Lodos ativados \\
\hline Sistema B & $\begin{array}{l}\text { Reator anaeróbio de manta } \\
\text { de lodo }\end{array}$ & Lagoa facultativa \\
\hline Sistema C & $\begin{array}{l}\text { Reator anaeróbio de manta } \\
\text { de lodo }\end{array}$ & Filtro biológico \\
\hline Sistema D & $\begin{array}{l}\text { Reator anaeróbio de manta } \\
\text { de lodo }\end{array}$ & $\begin{array}{c}\text { Lagoa aerada e lagoa de } \\
\text { decantação }\end{array}$ \\
\hline Sistema E & Lagoa anaeróbia & Lodos ativados \\
\hline Sistema F & Lagoa anaeróbia & Lagoa facultativa \\
\hline Sistema G & Lagoa anaeróbia & Filtro biológico \\
\hline Sistema H & Lagoa anaeróbia & $\begin{array}{c}\text { Lagoa aerada e lagoa de } \\
\text { decantação }\end{array}$ \\
\hline
\end{tabular}


Segundo Oliveira (2004), na composição dos custos houve a preocupação de se construir estações de tratamento com qualidade ambiental e paisagística, a fim de criar uma área agradável e de baixo impacto ambiental. Com esse intuito, todas as lagoas são impermeabilizadas para reduzir a percolação de poluentes no solo, o efluente final é clorado e desclorado para evitar contaminação do rio receptor, todas as áreas livres foram gramadas e ajardinadas, há coleta de águas pluviais, foi previsto um cinturão verde de $10 \mathrm{~m}$ de largura ao redor do terreno da estação, bem como instalação de equipamentos de coleta e queima de gás gerado nos reatores anaeróbios (metano) e equipamento para desaguamento do lodo. As composições de custos de obras de todos os sistemas foram desenvolvidas de acordo com orçamentos para obras prediais, pavimentação e tratamento paisagístico de entornos.

Após terem sidos realizados os cálculos inerentes a todos os sistemas, o modelo de Oliveira (2004) indica, por meio de uma árvore de decisão quantitativa, a alternativa de menor custo dentre os oito sistemas considerados como exemplificado pela Figura 2.

De acordo com a Figura 2, as ramificações que recebem o valor "falso" são aquelas nas quais os valores são maiores quando comparados às outras alternativas. A ramificação que recebe "verdadeiro", desde a extrema direita até a esquerda representará a escolha do modelo.

A técnica da árvore de decisão quantitativa considera as decisões e as chances de ocorrerem certos eventos por meio de cálculo do valor monetário esperado (VME) para cada alternativa. É um grafo composto por nós quadrados que representam as decisões a serem tomadas e nós em forma de círculos que representam as chances de cada alternativa (CLEMEN, 1996). Este grafo pode ser visto como um fluxo de decisão sequencial, em que na extrema direita estão os resultados condicionais e em suas ramificações a probabilidade esperada (COOPER; SCHINDLER, 2003, p. 571). Segundo Shimizu (2006), a árvore de decisão pode estruturar de maneira bastante clara qualquer problema de decisão, pois identifica as alternativas, as variáveis e os cenários possíveis. Essa técnica tem sido utilizada em vários tipos de problemas operacionais (HILLIER; LIEBERMAN, 2006).

O modelo de Oliveira (2004) foi avaliado e validado por Leoneti (2009). No trabalho de dissertação do autor, foram desenvolvidas 12 novas versões do modelo, sendo que nelas foi inserida uma planilha com o resumo total dos custos individuais das 21 variáveis de custo calculadas pelo modelo e os custos totais de cada sistema. Esta planilha de resumo, que pode ser visualizada na Figura 3, proporcionou outra forma de se verificar e comparar as respostas do modelo, diferentemente da árvore de decisão quantitativa, pois os custos totais foram ordenados dos menores aos maiores valores, recebendo cada sistema uma colocação.

\section{Simulação de Monte Carlo}

De acordo com Ragsdale (2004), simulação é um processo de quatro passos: identificar as variáveis incertas no modelo; implementar uma distribuição apropriada para cada variável incerta; reproduzir o modelo $\mathrm{n}$ vezes e registrar os valores medidos; e analisar os valores da amostra coletados na medida de desempenho.

Uma técnica muito utilizada para simular modelos de tomada de decisão é a simulação de Monte Carlo. O nome "Monte Carlo" faz menção aos jogos no cassino de Monte Carlo, na cidade de Mônaco, devido ao caráter aleatório destes. Este método permite gerar "valores probabilísticos ou aleatórios sobre os modelos que imitam ou simulam a realidade" (SHIMIZO, 2006, p. 116). Clemen (1996) afirma que se pode utilizar a simulação de Monte Carlo para descrever situações em que a incerteza é grande. Para isto, devem ser conhecidas as distribuições de probabilidade das variáveis do modelo que são consideradas incertas. Ao serem substituídos os valores de entrada do modelo por essas distribuições,

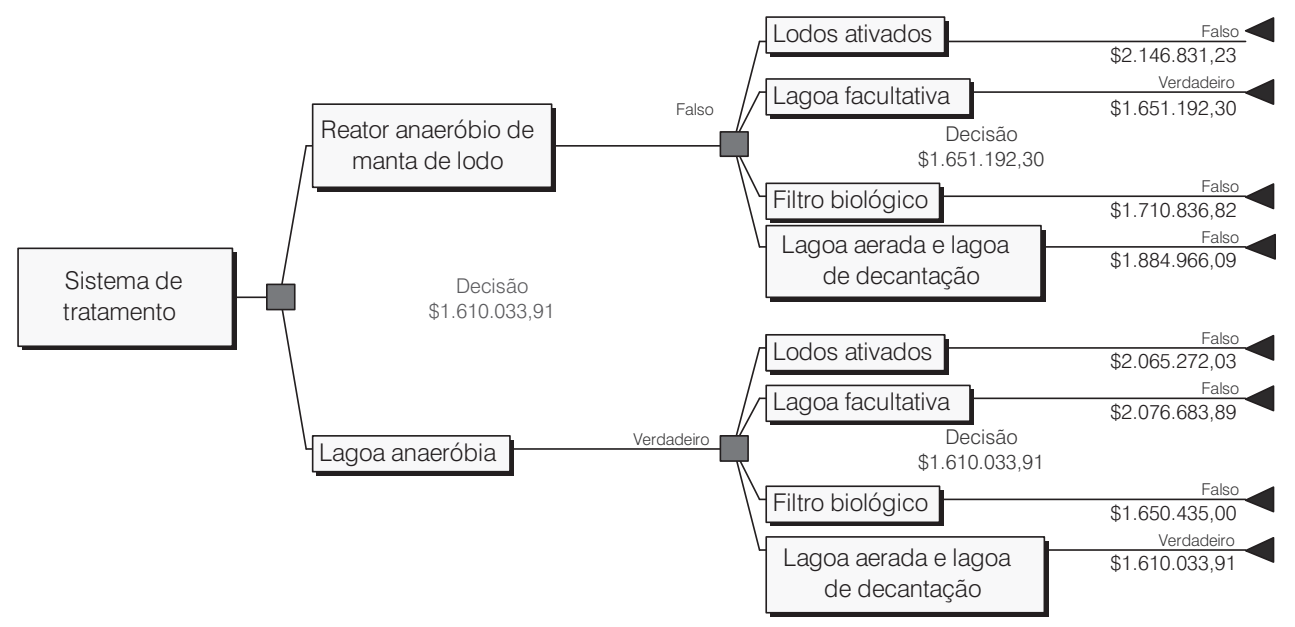

Figura 2 - Exemplo de árvore de decisão com escolha da melhor alternativa no modelo de Oliveira (2004) 


\begin{tabular}{|c|c|c|c|c|c|c|c|c|c|c|c|}
\hline & A & $\mathrm{B}$ & C & D & $E$ & $F$ & G & $\mathrm{H}$ & 1 & J & \\
\hline 1 & & & & & & & & & & & \\
\hline 2 & & & Sistema A & Sistema B & Sistema C & Sistema D & Sistema E & Sistema F & Sistema G & Sistema H & \\
\hline 3 & Item & Descriçäo & US\$ & US\$ & US\$ & US\$ & US\$ & US\$ & US\$ & US\$ & \\
\hline 4 & 1 & Terreno & 0,00 & 0,00 & 0,00 & 0,00 & 0,00 & 0,00 & 0,00 & 0,00 & \\
\hline 5 & 2 & Escavaçöes e limpeza do terreno & $190.674,44$ & $3.264 .761,83$ & $197.987,43$ & $2.079 .833,58$ & $1.823 .628,31$ & $25.927 .977,93$ & $1.943 .101,98$ & $4.597 .161,54$ & \\
\hline 6 & 3 & Valor de projetos ( $5 \%$ valor obra) & $763.127,38$ & $508.751,59$ & $635.939,48$ & $614.741,50$ & $614.741,50$ & $445.157,64$ & $572.345,54$ & $551.147,55$ & \\
\hline 7 & 4 & Tratamento preliminar & $1.030 .457,50$ & $1.030 .457,50$ & $1.030 .457,50$ & $1.030 .457,50$ & $1.030 .457,50$ & $1.030 .457,50$ & $1.030 .457,50$ & $1.030 .457,50$ & \\
\hline 8 & 5 & Fundaçöes (20\% concreto armado) & $461.126,79$ & $322.826,08$ & $502.141,20$ & $322.826,08$ & $257.757,20$ & 0,00 & $271.644,41$ & 0,00 & \\
\hline 9 & 6 & Paisagismo & $55.037,64$ & $173.953,23$ & $58.968,90$ & $74.945,89$ & $203.639,25$ & $177.266,05$ & $183.982,96$ & $166.236,13$ & \\
\hline 10 & 7 & Drenagem & $141.693,81$ & $671.761,10$ & $151.814,79$ & $289.421,09$ & $524.267,08$ & $912.739,09$ & $473.662,15$ & $641.959,69$ & \\
\hline 11 & 8 & Instalą̧öes elétricas & $275.735,29$ & 0,00 & 0,00 & $162.187,50$ & $323.988,97$ & 0,00 & 0,00 & $162.187,50$ & \\
\hline 12 & 9 & Segurança & $239.531,25$ & $250.495,58$ & $223.989,15$ & $225.120,97$ & $273.181,50$ & $282.073,22$ & $250.910,27$ & $248.838,98$ & \\
\hline 13 & 10 & Pára-raios & $29.441,64$ & $29.441,64$ & $29.441,64$ & $29.441,64$ & $29.441,64$ & $29.441,64$ & $29.441,64$ & $29.441,64$ & \\
\hline 14 & 11 & Redes de água, esgoto, água de serviço & $423.017,52$ & $372.142,37$ & $435.736,31$ & $425.137,32$ & $425.137,32$ & $340.345,39$ & $403.939,34$ & $393.340,35$ & \\
\hline 15 & 12 & Concreto armado & $2.305 .633,96$ & $1.614 .130,38$ & $2.510 .706,00$ & $1.614 .130,38$ & $1.675 .421,80$ & $47.365,89$ & $1.358 .222,06$ & $33.048,10$ & \\
\hline 16 & 13 & Impermeabilização & $609.240,75$ & $1.168 .273,10$ & $676.006,65$ & $811.500,20$ & $572.865,26$ & $1.629 .140,58$ & $582.493,14$ & $1.325 .101,05$ & \\
\hline 17 & 14 & Edificaçōes & $27.402,82$ & $13.701,41$ & $18.268,54$ & $22.835,68$ & $18.268,54$ & $4.567,14$ & $9.134,27$ & $13.701,41$ & \\
\hline 18 & 15 & Equipamentos & $2.126 .443,25$ & $1.585 .276,59$ & $2.291 .746,94$ & $1.947 .635,27$ & $2.082 .091,30$ & $1.324 .873,93$ & $2.239 .066,22$ & $1.687 .232,61$ & \\
\hline 19 & 16 & Teleforia/informática para automação & $588.832,86$ & $588.832,86$ & $588.832,86$ & $588.832,86$ & $588.832,86$ & $588.832,86$ & $588.832,86$ & $588.832,86$ & \\
\hline 20 & 17 & Vias de circulaçäo & $141.436,96$ & $670.543,41$ & $151.539,60$ & $288.896,46$ & $523.316,76$ & $911.084,59$ & $472.803,56$ & $640.796,03$ & \\
\hline 21 & 18 & Área de "cinturäo verde" & $137.857,57$ & $300.166,7 ?$ & $142.696,14$ & $197.024,52$ & $265.174,33$ & $214.261,50$ & $252.051,64$ & $293.433,08$ & \\
\hline 22 & 19 & Desinfecçäo & $1.177,665,71$ & $1.177 .665,71$ & $1.177 .665,71$ & $1.177 .665,71$ & $1.177 .665,71$ & $1.173,665,71$ & $1.177665,71$ & $1.177 .665,71$ & \\
\hline 23 & 20 & Estimativa do custo de operação & $8.327 .207,83$ & $3.220 .173,48$ & $7.916 .856,88$ & $8.866 .879,71$ & $10.291 .913,95$ & $3.800 .091,30$ & $10.418 .583,66$ & $7.600 .182,61$ & \\
\hline 24 & 21 & Depreciação de equipamentos & $1.155 .962,31$ & $861.777,05$ & $1.245 .823,55$ & $1.058 .759,96$ & $1.131 .852,01$ & $720.218,76$ & $1.217 .185,63$ & $917.201,67$ & \\
\hline 25 & & Custos por habitante & US\$ & US\$ & US\$ & US\$ & US\$ & US\$ & US\$ & US\$ & \\
\hline 26 & & Custo total por habitante & 47,66 & 51,48 & 47,14 & 51,49 & 56,22 & 93,32 & 55,37 & 52,12 & \\
\hline 27 & & Custo de implantação por habitante & 25,30 & 32,42 & 25,53 & 28,07 & 29,27 & 82,66 & 27,93 & 32,03 & \\
\hline 28 & & Resumo dos custos & US\$ & US\$ & US\$ & US\$ & US\$ & US\$ & US\$ & US\$ & \\
\hline 29 & & Estimativa de custo de implantação & $10.724 .357,14$ & $13.743 .181,13$ & $10.823 .938,86$ & $11.902 .634,15$ & $12.409 .876,84$ & $35.043 .250,65$ & $11.839 .755,24$ & $13.580 .581,72$ & \\
\hline 30 & & Estimativa de custo de operaçăo e manutençăo & $9.483 .170,14$ & $8.081 .950,52$ & $9.162 .680,44$ & $9.925 .639,67$ & $11.423 .765,96$ & $4.520 .310,07$ & $11.635 .769,29$ & $8.517 .384,28$ & \\
\hline 31 & & Custo total do sistema & US\$ & US\$ & US\$ & US\$ & US\$ & US\$ & US\$ & US\$ & \\
\hline 32 & & Custo total do sistema & $20.207 .527,27$ & $21.825 .131,65$ & $19.986 .619,30$ & $21.828 .273,82$ & $23.833 .642,80$ & $39.563 .560,71$ & $23.475 .524,53$ & $22.097 .966,01$ & \\
\hline 33 & & Ordem & 2 & 3 & 1 & 4 & 7 & 8 & 6 & 5 & \\
\hline 34 & & & & & & & & & & & \\
\hline 35 & & & Sistema A & Sistema B & Sistema C & Sistema D & Sistema E & Sistema F & Sistema G & Sistema $\mathbf{H}$ & \\
\hline 36 & & Eficiências & $\mathrm{mg} / \mathrm{L}$ & $\mathrm{mg} / \mathrm{L}$ & $\mathrm{mg} / \mathrm{L}$ & $\mathrm{mg} / \mathrm{L}$ & $\mathrm{mg} / \mathrm{L}$ & $\mathrm{mg} / \mathrm{L}$ & $\mathrm{mg} / \mathrm{L}$ & $\mathrm{mg} / \mathrm{L}$ & \\
\hline 37 & & Estimativa DBO efluente & 9 & 18 & 22 & 31 & 16 & 33 & 46 & 38 & \\
\hline 38 & & Ordem & 1 & 3 & 4 & 5 & 2 & 6 & 8 & 7 & \\
\hline 39 & & Dimensionamento & $\mathrm{m}^{2}$ & $\mathrm{~m}^{2}$ & $\mathrm{~m}^{2}$ & $\mathrm{~m}^{2}$ & $\mathrm{~m}^{2}$ & $\mathbf{m}^{2}$ & $\mathrm{~m}^{2}$ & $\mathrm{~m}^{2}$ & \\
\hline 40 & & Area total & 83.096 & 393.953 & 89.032 & 169.731 & 307.456 & 802.911 & 277.778 & 376.476 & \\
\hline 41 & & Ordem & 1 & 7 & 2 & 3 & 5 & 8 & 4 & 6 & \\
\hline
\end{tabular}

Figura 3 - Exemplo da planilha de resumo com escolha da melhor alternativa no modelo de Oliveira (2004)

as variáveis tornam-se aleatórias e a simulação deve ser realizada muitas vezes até que se consiga uma aproximação para a distribuição de probabilidade dos pagamentos para as diversas alternativas do modelo. "Quanto mais simulações pudermos realizar, maior a precisão desta aproximação" (CLEMEN, 1996, p. 413).

Uma possibilidade de se atingir maior precisão no processo da simulação de Monte Carlo é a utilização de softwares de simulação em modelos desenvolvidos sob a forma de planilhas eletrônicas. Um software considerado adequado para esta tarefa é o Crystal Ball ${ }^{\circledR}$. Ele possui 16 diferentes famílias de distribuições, incluindo uma personalizável "que pode ser usada para criar uma distribuição de qualquer forma" (CLEMEN, 1996, p. 418).

\section{Teoria dos jogos e equilíbrio de Nash}

A teoria dos jogos:

é uma teoria matemática que trata das características gerais de situações competitivas [...], ela coloca particular ênfase nos processos de tomada de decisão dos jogadores. (HILLIER; LIEBERMAN, 2006, p. 641).
Sua metodologia permite que esta teoria seja utilizada para clarificar os fenômenos econômicos, políticos e biológicos e a maioria das situações cotidianas, que são abstraídas na forma de modelos, os quais tornam factível a avaliação das vantagens e das desvantagens das várias estratégias possíveis, considerando aquelas dos outros indivíduos envolvidos nessa mesma situação (OSBORNE, 2004). Na prática, esta teoria pode auxiliar no entendimento de situações nas quais tomadores de decisão se interagem. "Muitos dos problemas de decisão podem ser pensados como jogos" (BIERMAN; FERNANDEZ, 1998, p. 4)

Segundo Bierman e Fernandez (1998), um jogo pode ser descrito usando um formulário onde, em seu topo, estão os nomes dos jogadores. Em seguida, em cada linha, são dispostas as estratégias de cada jogador com seus respectivos pagamentos, ou seja, o quanto o jogador ganhará adotando esta estratégia. Ainda, segundo os autores, é mais conveniente apresentar os pagamentos dos jogadores na forma de uma tabela de pagamentos. A Figura 4 apresenta uma tabela de pagamentos para um jogo fictício com dois jogadores. O jogador 1 possui seus pagamentos representados pelas letras "A, B, C e D", enquanto o jogador 2 possui seus pagamentos representados pelos números " $1,2,3$ e 4 ". 
Quando os jogadores não podem estabelecer compromissos garantidos, diz-se que o jogo é "não-cooperativo", caso contrário, diz-se "cooperativo". Jogos em que as recompensas dos jogadores estão relacionadas de forma inversa, ou seja, o ganho de um jogador implica necessariamente na perda para o outro, constitui os chamados "jogos estritamente competitivos" ou "jogos de soma zero". Todavia, uma característica comum de todos estes jogos é a presença de decisões estratégicas por parte dos jogadores, o que denomina estes jogos como "jogos de estratégia".

De forma geral, a teoria dos jogos pode ser um meio para se identificar os resultados de um jogo de estratégias. Quando algum resultado é a "combinação das estratégias que são as melhores respostas umas às outras" (FIANI, 2006, p. 93), considera-se que foi encontrado o equilíbrio de Nash. No equilíbrio de Nash os jogadores têm o conhecimento sobre as estratégias dos seus concorrentes e escolhem a melhor estratégia possível, levando em consideração as escolhas de todos os outros jogadores estabelecendo-se, então, uma situação na qual nenhum dos participantes tem incentivo a mudar de estratégias.

Segundo Varian (2003), quando em um jogo existam nas linhas as escolhas $l_{1}, l_{2}, \ldots, l_{L}$, e na coluna as escolhas $c_{1}, c_{2}, \ldots, c_{C}$, e para cada escolha "l" feita por linha, seja $b_{c}(1)$ haja uma melhor resposta para coluna, e para escolha "c" feita por coluna, seja $b_{1}(c)$ haja uma melhor resposta para a linha, diz-se ter encontrado um equilíbrio de Nash, que é um par de estratégias $\left(1^{*}, c^{*}\right)$ tal que: $c^{*}$ $=b_{c}\left(l^{*}\right) ; e l^{*}=b_{1}\left(c^{*}\right)$. De outra forma, para que uma combinação de estratégias seja considerada um equilíbrio de Nash é necessário que, para cada estratégia $\mathrm{s}_{\mathrm{i}}{ }^{*}$, tenhamos $\mathrm{f}_{\mathrm{i}}\left(\mathrm{s}_{\mathrm{i}}{ }^{*}, \mathrm{~S}_{-\mathrm{i}}{ }^{*}\right)>=\mathrm{f}_{\mathrm{i}}\left(\mathrm{s}_{\mathrm{i}}, \mathrm{s}_{-\mathrm{i}}\right)$, para todo $s_{i}$ e todo $i$, onde $f_{i}$ é a função de recompensa para cada jogador i (FIANI, 2006).

A noção de equilíbrio de Nash possui certa lógica, mas também alguns problemas, como a característica de alguns jogos possuírem mais de um equilíbrio de Nash. Quando os agentes atribuem uma probabilidade para cada estratégia e escolhe a frequência ótima para jogá-las, dadas as frequências das escolhas dos outros agentes, tem-se o tipo de estratégia chamado de "estratégia mista”. Neste caso sempre existirá o equilíbrio de Nash. Todavia, quando os agentes escolhem uma estratégia de forma definitiva, ou seja, cada agente faz uma escolha e a mantém, tem-se o tipo de estratégia chamada "estratégia pura", na qual, para alguns casos, não existe, de forma absoluta, o equilíbrio de Nash, representando isto o segundo maior problema desta teoria (VARIAN, 2003).

Ademais, o conceito do equilíbrio de Nash não implica que a situação resultante das decisões conjuntas seja a melhor possível. Quando a situação de pelo menos um jogador pode melhorar, sem que a situação de nenhum dos outros jogadores piore, diz-se que houve uma melhoria paretiana, ou uma melhoria no sentido de Pareto. Todavia, o conceito do equilíbrio de Nash permanece útil para a compreensão dos jogos simultâneos, principalmente porque este conceito procura captar as situações em que os agentes não teriam estímulos para mudar suas decisões (FIANI, 2006).

\section{Metodologia}

Seguindo os quatro passos preliminares para a realização de simulações, propostos por Ragsdale (2004), primeiramente, foram identificadas as variáveis de entrada do modelo de Oliveira (2004), as quais sofreram algum tipo de variação, dentre os valores das observações levantadas em 12 projetos de sistemas de

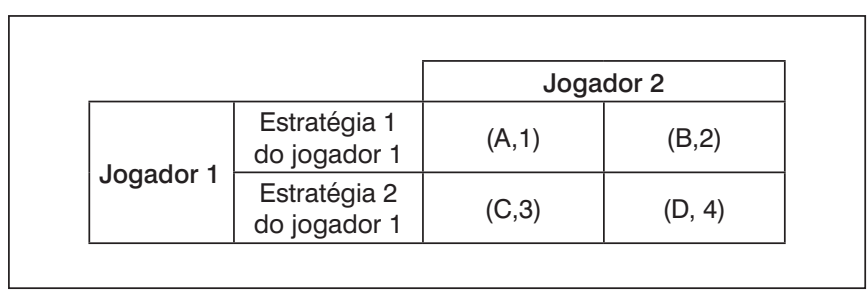

Figura 4 - Exemplo de uma tabela de pagamentos

Tabela 1 - Variáveis de entrada do modelo de Oliveira (2004) e parâmetros de projeto utilizados

\begin{tabular}{|c|c|c|c|c|c|c|c|}
\hline $\begin{array}{l}\text { Projeto de estação de } \\
\text { tratamento de esgoto }\end{array}$ & $\begin{array}{c}\text { População } \\
\text { estimada } 2025\end{array}$ & $\begin{array}{l}\text { Vazão afluente } \\
\text { média }\end{array}$ & $\begin{array}{l}\text { Vazão afluente } \\
\text { máxima }\end{array}$ & $\begin{array}{l}\text { DBO média } \\
\text { afluente }\end{array}$ & $\begin{array}{l}\text { Alcance do } \\
\text { projeto }\end{array}$ & $\begin{array}{l}\text { Classe do rio } \\
\text { receptor }\end{array}$ & $\begin{array}{l}\text { Temperatura do } \\
\text { mês mais frio }\end{array}$ \\
\hline Cidade & hab & $\mathrm{m}^{3} / \mathrm{d}$ & $\mathrm{m}^{3} / \mathrm{d}$ & $\mathrm{mg} / \mathrm{L}$ & anos & classe & ${ }^{\circ} \mathrm{C}$ \\
\hline Ibiporanga & 1.093 & 196 & 235 & 233 & 20 & 2 & 23 \\
\hline Ecatu-Tanabi & 1.606 & 307 & 368 & 282 & 20 & 2 & 23 \\
\hline Mirassolândia & 5.169 & 1.009 & 1.210 & 266 & 20 & 2 & 22 \\
\hline Cruz das Posses & 10.463 & 1.689 & 1.950 & 307 & 20 & 3 & 18 \\
\hline Caconde & 28.394 & 4.406 & 7.862 & 313 & 20 & 2 & 18 \\
\hline Casa Branca & 29.602 & 4.940 & 8.982 & 341 & 20 & 3 & 23 \\
\hline Rio das Pedras & 31.604 & 6.048 & 7.257 & 280 & 20 & 3 & 22 \\
\hline Descalvado & 35.709 & 6.307 & 7.516 & 275 & 20 & 2 & 22 \\
\hline Barrinha & 37.299 & 7.240 & 8.689 & 278 & 20 & 2 & 18 \\
\hline Ituverava & 39.515 & 7.344 & 8.640 & 290 & 20 & 4 & 18 \\
\hline Américo Brasiliense & 46.740 & 9.250 & 11.059 & 273 & 20 & 2 & 18 \\
\hline Vargem Grande do Sul & 51.595 & 9.597 & 13.600 & 302 & 20 & 2 & 17 \\
\hline
\end{tabular}

Fonte: Projetos fornecidos pelo DAEE de Ribeirão Preto e Prefeitura Municipal de Vargem Grande do Sul, São Paulo. 
tratamento de esgoto de municípios paulistas. Estes projetos foram disponibilizados pelo Departamento de Água e Energia Elétrica (DAEE) de Ribeirão Preto e pela prefeitura municipal de Vargem Grande do Sul, e representam uma amostra de conveniência, pois eles foram relativos ao projeto "Água Limpa", que são mais recentes e possuem maior acessibilidade aos dados. Todavia, esta amostra contemplou quase toda a faixa de população de mil até 50 mil habitantes, o que permitiu a aplicação do método proposto. Os parâmetros coletados podem ser visualizados na Tabela 1 .

Dentre as variáveis de entrada do modelo de Oliveira (2004), a variável 'alcance do projeto' recebeu um valor constante, pois não se alterou em nenhuma das 12 observações consideradas. $\mathrm{O}$ valor adotado foi de 20 anos, pois foi este o parâmetro utilizado em todos os projetos. Já a variável 'classificação do rio receptor', foi considerada como classe 2 , que é o valor mais restritivo dentre todos os projetos.

O próximo passo foi a definição de uma distribuição de probabilidade apropriada para cada uma das outras variáveis. Esta definição foi realizada avaliando-se a variação apresentada em cada uma das variáveis, tendo como base os 12 projetos coletados. A variável 'população estimada 2.025' recebeu valores aleatórios, com distribuição uniforme, entre 500 e 100 mil habitantes, para cobrir a faixa de população das 12 cidades. As variáveis 'vazão afluente média' e 'vazão afluente máxima' receberam, respectivamente, 18 e 24\% do valor da variável 'população estimada 2025', ou seja, caso a variável 'população estimada 2025' recebesse 10 mil habitantes, a variável 'vazão afluente média' receberia 1.800 $\mathrm{m}^{3} /$ dia e a 'vazão afluente máxima' receberia $2.400 \mathrm{~m}^{3} /$ dia, o que tornou as suas distribuições também uniformes. A variável 'DBO média afluente' se apresentou como uma distribuição normal, de média 287 e desvio padrão 27 e foi esta distribuição que a variável recebeu na simulação. Por fim, a variável 'temperatura do mês mais frio', assim como a variável 'DBO média afluente', tinha o comportamento de uma distribuição normal e recebeu os valores de 20 para a média e 2 para o desvio padrão.

Cabe aqui ressaltar que os passos para a definição das variáveis, bem como o levantamento de alguns projetos, foram necessários, pois pretendeu-se utilizar o modelo de Oliveira (2004) como ferramenta para se estimar, principalmente, os custos dos sistemas. Portanto, estes passos até aqui seriam desnecessários em outras aplicações que não utilizassem este modelo. Por exemplo, poder-se-ia utilizar dados da literatura para fazer uma estimativa de preços e de índices de eficiência para cada sistema de tratamento. A vantagem na utilização do modelo foi a qualidade da sua estimativa de custo, a qual foi verificada no estudo de Leoneti (2009).

Após a definição das distribuições probabilísticas das variáveis, a planilha com os dados de entrada do modelo de Oliveira (2004) foi configurada apropriadamente com o auxílio do software Crystal
Ball $^{\circledR}$. Este procedimento já era suficiente para realizar a simulação do modelo e verificar o comportamento de suas respostas para a faixa de população da amostra.

Todavia para encontrar o equilíbrio de Nash, que seria uma solução que considerasse o conflito entre eficiência e custo, diferente da resposta de menor custo total proposta pelo modelo, foi criada uma matriz onde foram inseridos os custos totais dos sistemas e suas estimativas de DBO no efluente final calculados pelo modelo de Oliveira (2004). Esta matriz representou a tabela de custo e eficiência, na qual os valores representaram os ganhos dos jogadores "econômico" e "ecológico", respectivamente.

Tendo em vista o crescente emprego com sucesso da associação de sistemas anaeróbios, seguidos de aeróbios (CAMPOS et al, 1997; CHERNICHARO, 2001), no contexto deste trabalho, achou-se conveniente restringir a escolha do jogador "ecológico" como a escolha do primeiro processo e a escolha do jogador "econômico" como a escolha do segundo processo de tratamento. Desta forma, a tabela de custo e eficiência, que a princípio seria da ordem de seis linhas por seis colunas pois consideraria a combinação de todos os seis sistemas do modelo de Oliveira (2004), passou a contar com apenas as duas alternativas de sistemas anaeróbios (UASB e Lagoa Anaeróbia) para o jogador "ecológico", representando o primeiro processo de tratamento, e as quatro alternativas de sistemas aeróbios (Lodos Ativados, Lagoa Facultativa, Filtro Biológico e Lagoa Aerada) para o jogador "econômico", representando o segundo processo de tratamento. A combinação de cada uma destas alternativas correspondeu a cada um dos sistemas do modelo.

Ainda poderiam ter sido eliminadas as alternativas de sistemas menos usuais que são contempladas pelo modelo Oliveira (2004), a saber: o "Sistemas E" (lagoa anaeróbia seguida de lodo ativado) e o "Sistema G" (lagoa anaeróbia seguida de filtro biológico), pois dificilmente são adotados como sistema de tratamento de esgoto nos municípios. Mas, com o intuito de facilitar a implantação da metodologia com a utilização do modelo, estes arranjos de sistemas foram mantidos.

A partir da definição da tabela de custo e eficiência em forma de matriz no Excel, o equilíbrio de Nash foi calculado conforme proposto por Varian (2003), ou seja, comparando se para cada escolha feita por linha havia uma melhor resposta para a coluna, e se para cada escolha feita por coluna havia uma melhor resposta para a linha. Esta comparação foi realizada utilizando as funções de comparações disponíveis no software Excel.

Por fim, foram realizadas mil simulações utilizando as configurações realizadas no software Crystal Ball ${ }^{\circledR}$, com populações variando entre 500 e 100 mil habitantes, concretizando o terceiro passo definido por Ragsdale (2004). Para cada um dos mil cenários diferentes, foram comparadas as respostas do modelo de Oliveira (2004) com as do equilíbrio de Nash. 


\section{Resultados e discussões}

No contexto deste trabalho, foram definidos dois jogadores: o "ecológico", que prioriza uma solução de menor impacto ambiental; e o "econômico", que prioriza uma de menor custo. Tendo em vista que o único impacto ambiental considerado nesta pesquisa foi a quantidade de DBO no efluente final, para encontrar o equilíbrio de Nash, que poderia solucionar o conflito entre estes dois jogadores, foi necessário criar uma tabela de pagamentos, com base nos dados de saída do modelo de Oliveira (2004), na qual constassem as estimativas de DBO no efluente, que são os valores referentes ao jogador "ecológico", e os custos totais do sistema, que são os valores referentes ao jogador "econômico". Esta tabela de custo e eficiência criada é semelhante àquela visualizada na Figura 5 .

A primeira entrada de cada par de valores das células corresponde ao ganho do jogador "ecológico", ou seja, são as estimativas de DBO no efluente final do sistema. Da mesma forma, a segunda entrada mostra os ganhos do jogador "econômico", que são os custos totais do sistema. Por exemplo, na última linha e na última coluna da Figura 5, seriam alocados os valores referentes ao "Sistema H" do modelo de Oliveira (2004). O valor do lado esquerdo representa, em mg/L, a estimativa de DBO efluente, enquanto o lado direito representa o custo total do "Sistema H", em dólares. Cada um dos dois jogadores pretende minimizar os valores presentes em seu lado de cada par de elementos da tabela de pagamentos.

Para verificar se a partir da tabela de custo e eficiência poderia ser encontrado o equilíbrio de Nash, foram realizados alguns testes utilizando os dados dos projetos coletados. Por exemplo, para o município de Casa Branca, com população estimada em 29.602 habitantes, vazão média afluente de $4.940 \mathrm{~m}^{3} /$ dia, vazão máxima afluente de $8.982 \mathrm{~m}$ 3/dia, DBO média afluente de $341 \mathrm{mg} / \mathrm{L}$, alcance do projeto de 20 anos, rio receptor classe 3 e temperatura do mês mais frio $23^{\circ}$ C, seus parâmetros foram inseridos na planilha dos dados de entrada do modelo de Oliveira (2004) e, com base nos custos e quantidade de DBO efluente calculados pelo modelo, foi gerada a tabela da Figura 6 , com os dados das primeiras entradas de cada par de elementos em $\mathrm{mg} / \mathrm{L}$ e os das segundas em milhares de dólares, a partir da qual foi possível encontrar o equilíbrio de Nash no "Sistema B" (valor destacado na Figura 6).

Na tabela da Figura 6, os valores sublinhados são aqueles escolhidos pelos jogadores "ecológico" e "econômico". O equilíbrio de Nash acontece quando existe pelo menos um par de elementos que estão conjuntamente sublinhados (FIANI, 2006).

O sistema instalado no município de Casa Branca foi o Sistema Australiano. O Sistema Australiano é o nome dado para o conjunto de duas lagoas, a primeira anaeróbia e a segunda facultativa. Este sistema é representado no modelo de Oliveira (2004) pelo "Sistema
F". No entanto, a escolha de menor custo indicada pelo modelo de Oliveira (2004) para o município de Casa Branca foi o "Sistema H", com uma lagoa anaeróbia como primeiro processo e uma lagoa facultativa aerada, como segundo processo. Neste caso, a escolha do modelo de Oliveira (2004), que é a de menor custo, não foi a mesma solução proposta pelo equilíbrio de Nash, que foi o "Sistema B", conforme a Figura 6.

A título de exemplo, uma tabela semelhante também poderia ser criada sem a utilização do modelo de Oliveira (2004), sendo a estimativa de DBO no efluente final e o custo total de cada sistema calculado com base em índices de eficiência e estimativas de custos de sistemas de tratamento de esgoto encontrados na literatura. Por exemplo, para os mesmos dados do município de Casa Branca, considerando os limites inferiores da tabela de características dos principais sistemas de tratamento de esgotos, proposta por Von Sperling (2006), a tabela de custo e eficiência poderia ser definida com base na multiplicação do tamanho da população (29.602 habitantes) pelo custo de implantação, em reais, por habitante de cada sistema, o que representaria os pagamentos para o jogador "econômico", e com base na multiplicação do DBO médio afluente (341 mg/L) pela eficiência média de remoção em porcentagem, o que representaria os pagamentos para o jogador "ecológico". A nova tabela pode ser visualizada na Figura 7

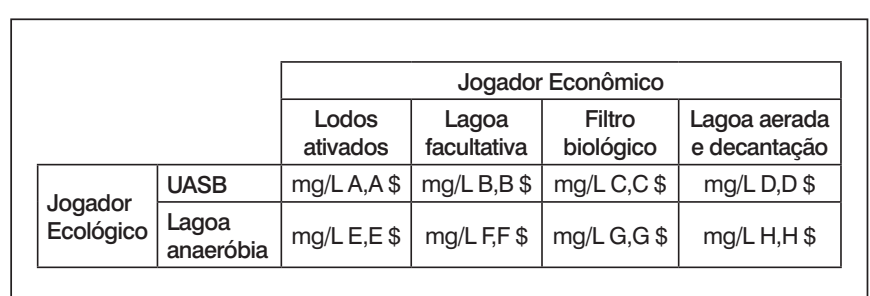

Figura 5 - Tabela de custo e eficiência dos jogadores "ecológico" e "econômico"

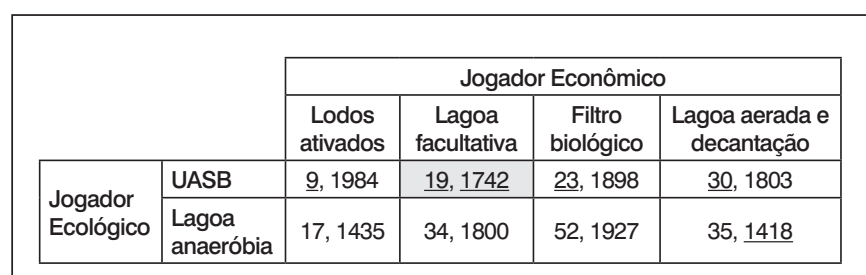

Figura 6 - Tabela de custo e eficiência para o município de Casa Branca

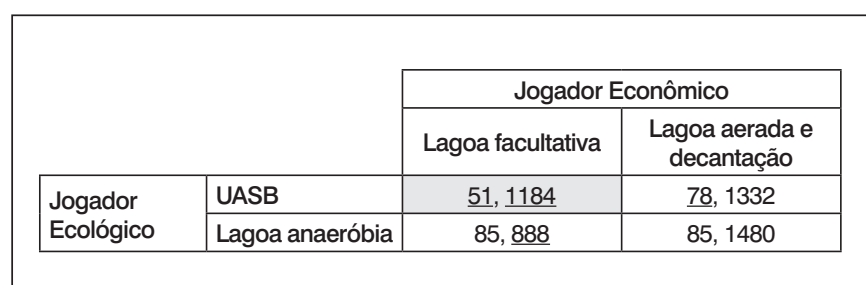

Figura 7 - Exemplo de tabela de custo e eficiência sem a utilização do modelo de Oliveira (2004) 


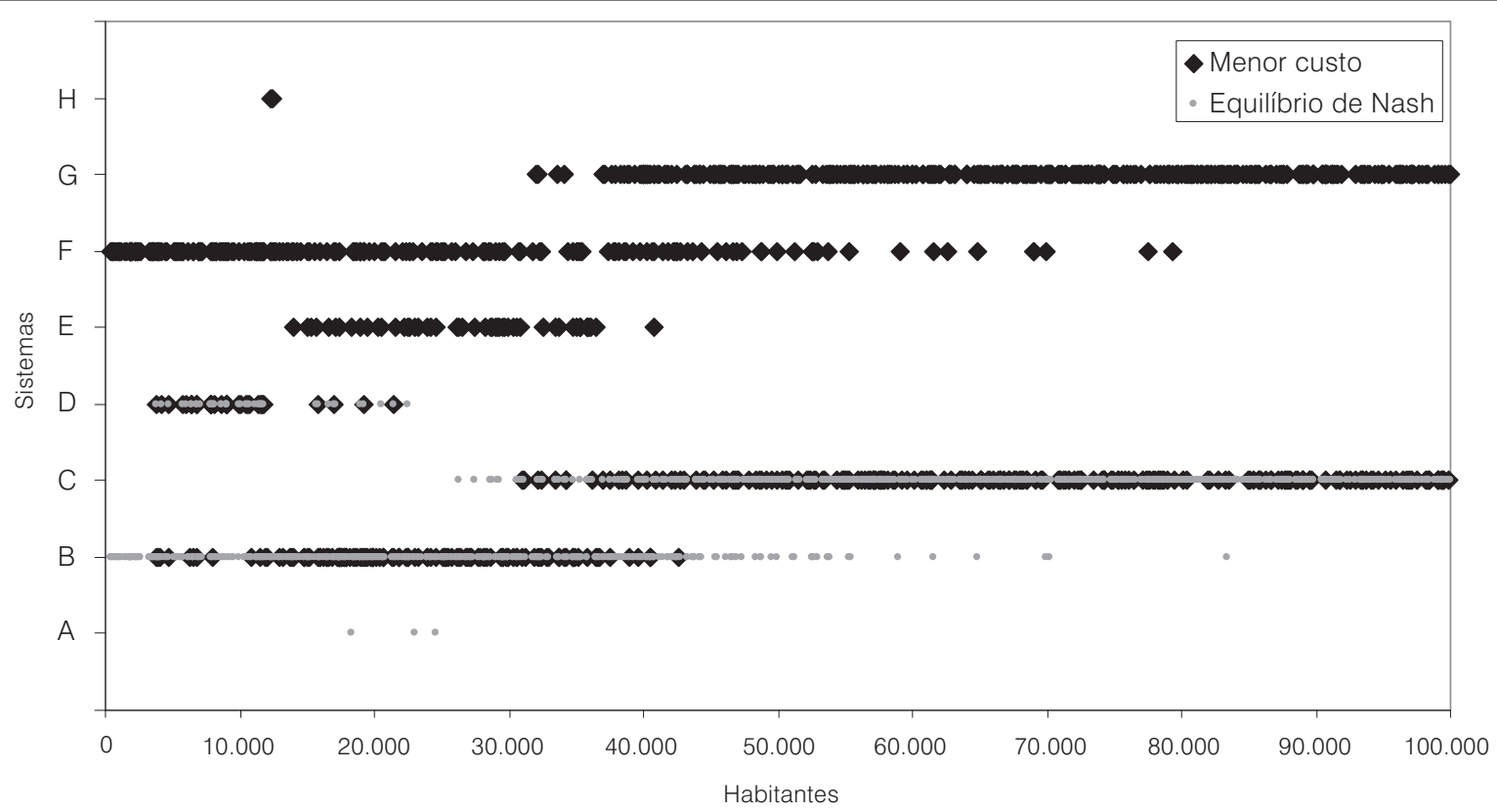

Figura 8 - Comparação da alternativa de menor custo indicada pelo modelo com o equilíbrio de Nash

Na tabela da Figura 7, o equilíbrio de Nash ocorreu para o sistema UASB + Lagoa Facultativa e o menor custo total foi alcançado pelo sistema Lagoa Anaeróbia + Lagoa Facultativa. A diferença nas duas soluções, quando considerado apenas o critério de menor custo e quando considerado os critérios de menor custo e eficiência, demonstra de forma simplificada a aplicação e viabilidade da metodologia. Cabe ressaltar que esta nova tabela é apenas um exemplo, não sendo apropriada a comparação de seus valores com os valores da tabela da Figura 6.

Após esses testes iniciais, a tabela de custo e eficiência foi inserida no modelo de Oliveira (2004), sendo os equilíbrios encontrados em conjunto com o cálculo dos custos dos sistemas. Isto possibilitou a coleta dos dados que foram gerados a partir de uma nova simulação, com mil iterações. Os dados coletados desta nova simulação estão expostos na Figura 8.

Ao final da simulação, foi identificado que o sistema UASB da primeira linha da tabela de custo e eficiência foi sempre escolhido como primeiro processo. Segundo Fiani (2006), quando o equilíbrio de Nash é encontrado entre as combinações de apenas uma linha ou coluna, o equilíbrio encontrado é denominado um equilíbrio de Nash estrito. Esta afirmação é valida apenas no contexto da aplicação com a utilização do modelo.

Para populações inferiores a 50 mil habitantes, a predominância dos equilíbrios de Nash ocorreu para o "Sistema B" (em que se encontram os pontos em cinza claro na linha destes sistemas), o que poderia ser uma evidência de que um sistema de tratamento que combine reator e lagoa seja o mais adequado para o tratamento de esgoto de municípios com uma população menor ou igual a este número de habitantes. No entanto, a partir de 50 mil habitantes o equilíbrio de Nash também ocorreu para o "Sistema C", sendo este sistema composto por dois reatores, o que poderia representar outro tipo de solução viável para uma faixa de população diferente.

Também de acordo com a Figura 8, o modelo de Oliveira (2004) distribuiu suas soluções predominantemente em cinco sistemas diferentes, que se encaixaram em diferentes faixas de população (onde se encontram os pontos em preto na linha destes sistemas). O "Sistema B", que é composto por um reator UASB e uma lagoa anaeróbia, foi escolhido pelo modelo na faixa entre 10 até 40 mil habitantes. A partir de 30 mil habitantes o "Sistema C", composto por um reator UASB e um filtro biológico, passou a ser escolhido pelo modelo. O "Sistema D", composto por um reator UASB no primeiro processo e uma lagoa aerada, seguida de uma lagoa de decantação no segundo processo, foi escolhido pelo modelo na faixa entre 3 até 11 mil habitantes, com alguns pontos na faixa entre 17 e 21 mil habitantes. O "Sistema G", o qual combina uma lagoa anaeróbia com um filtro biológico, foi escolhido a partir de 30 mil habitantes. Por fim, o "Sistema F", que é o Australiano, o qual foi implantado em 11 dos 12 municípios analisados, foi escolhido pelo modelo para uma grande faixa de população, desde 500 até 60 mil habitantes, possuindo também alguns pontos na faixa entre 70 e 80 mil habitantes.

As iterações realizadas puderam apresentar as distribuições dos possíveis resultados, o que corrobora com a afirmação feita por Clemen (1996). Levando-se em consideração que, o Sistema Australiano foi implantado na maioria dos 12 municípios, todos com populações inferiores a 50 mil habitantes, e que, de forma semelhante, a maioria das respostas propostas pelo modelo de 
Oliveira (2004) para esta faixa de população foi o "Sistema F" (Sistema Australiano), a adoção do equilíbrio de Nash propôs uma solução distinta das adotadas. No equilíbrio de Nash, o sistema mais indicado para a faixa da população entre 500 e 40 mil habitantes foi o "Sistema B" e a partir de 40 mil habitantes, o "Sistema C", fato este que poderia tornar esta metodologia como uma nova ferramenta que poderia ser considerada pelos tomadores de decisão como auxílio nas escolhas de sistema de tratamento de esgoto sanitário.

\section{Conclusões}

O objetivo principal desta pesquisa foi, com base nos dados de saída de um modelo de tomada de decisão, encontrar o equilíbrio de Nash para propor uma solução para o conflito entre eficiência e custo nas escolhas de sistema de tratamento de esgoto sanitário. Não obstante deste não ser o único conflito que surge quando são considerados mais de um critério, almejou-se propor uma metodologia para auxiliar a tomada de decisão.

A despeito de o modelo utilizado possuir, dentre as suas oito alternativas, dois arranjos de sistemas de tratamento de esgoto nãousuais, foi possível, a partir da definição das distribuições de probabilidade das variáveis de entrada do modelo de Oliveira (2004), estimadas com base em 12 projetos de sistemas de tratamento de esgoto coletados, criar uma tabela de custo e eficiência para os jogadores "ecológico" e "econômico". Esta tabela permitiu testar a metodologia e encontrar o equilíbrio de Nash para cada iteração da simulação do modelo de Oliveira (2004).

Em sua simulação, o modelo de Oliveira (2004) distribuiu suas soluções em predominantemente cinco tipos de sistemas, com cada um atendendo a uma determinada faixa de população. O "Sistema F", que combina duas lagoas no processo de tratamento de esgoto, foi o mais escolhido pelo modelo e o "Sistema B", o qual combina um reator no primeiro processo e uma lagoa no segundo, foi o que mais alcançou o equilíbrio de Nash, para os mil cenários diferentes, gerados pela simulação com o auxílio do software Crystal Ball ${ }^{\circledR}$. Este fato demonstra os diferentes resultados alcançados, quando considerando apenas o critério de menor custo, proposto pelo modelo, e os critérios de menor custo e de eficiência, propostos pelo equilíbrio de Nash.

A adoção do equilíbrio de Nash se mostrou uma alternativa viável para solucionar o conflito entre eficiência e custo nas escolhas das estações de tratamento de esgoto sanitário, visando atingir a melhor alternativa possível.

\section{Agradecimentos}

À Fundação de Amparo à Pesquisa do Estado de São Paulo (Fapesp) pela Bolsa de Mestrado; ao DAEE de Ribeirão Preto, representado pelos estimados engenheiros Carlos Eduardo Alencastre, Renato Crivelenti e Adolfo Monteiro Moraes, pelos diversos dados fornecidos; à José Rafael Pereira, pelas dicas sobre o equilíbrio.

\section{Referências}

BIERMAN, H.S.; FERNANDEZ, L. Game theory with economic applications. 2.ed. United States: Addison-Wesley, 1998.

BRASIL. IBGE - INSTITUTO BRASILEIRO DE GEOGRAFIA E ESTATÍSTICA. Pesquisa Nacional de Saneamento Básico, 2000. Disponível em: <http://www.ibge.gov.br/home/estatistica/populacao/ condicaodevida/pnsb/default.shtm > . Acesso em: 7 set. 2007.

CAMPOS, J.R. et al. Conceitos gerais sobre técnicas de tratamento de águas de abastecimento, esgotos sanitários e desinfecção. 43f. Dissertação de Mestrado - Escola de Engenharia de São Carlos, Universidade de São Paulo, São Carlos, 1997.

CHERNICHARO, C.A.L. (Coord.) et al. Pós-tratamento de efluentes de reatores anaeróbios. Belo Horizonte: Departamento de Engenharia Sanitária e Ambiental - Universidade Federal de Minas Gerais, 2001.

CLEMEN, R.T. Making hard decisions: an introduction to decision analysis. 2. ed. Belmont, CA: Duxburry Press, 1996

COOPER, D.R.; SCHINDLER, P.S. Métodos de pesquisa em administração. 7 ed. Porto Alegre: Bookman, 2003.
FIANI, R. Teoria dos jogos. 2. ed. Rio de Janeiro: Elsevier, 2006.

HILLIER, F.S.; LIEBERMAN, G.L. Introdução à pesquisa operacional. 8. ed. São Paulo: McGraw-Hill, 2006.

LACHTERMACHER, G. Pesquisa operacional na tomada de decisões: Para cursos de Administração, Economia e Ciências Contábeis. 2. ed. Rio de Janeiro: Campus, 2004.

LEONETI, A.B. Avaliação de modelo de tomada de decisão para escolha de sistema de tratamento de esgoto sanitário. 2009. 154f. Dissertação (Mestrado em Administração de Organizações) - Faculdade de Economia, Administração e Contabilidade de Ribeirão Preto, Universidade de São Paulo, Ribeirão Preto, 2009.

LOETSCHER, T. Working with you towards appropriate water supply and sanitation. Disponível em: <http://www.decisionscape.com.au/>. Acesso em: 17 abr. 2003

MCGAHEY, C. Water and Wastewater Treatment Technologies Appropriate for Reuse WAWTTAR. Disponível em: <http://firehole.humboldt.edu/ wawttar/wawttar.html>. Acesso em: 18 abr. 2003. 
MASSUKADO, L. M.; ZANTA, V. M. "SIMGERE": Software para avaliação de cenários de gestão integrada de resíduos sólidos domiciliares. Revista Engenharia Sanitária e Ambiental, v. 11, n. 2, p. 133-142, abr./jun. 2006.

MIRANDA, A.B.; TEIXEIRA, B.A.N. Indicadores para o monitoramento da sustentabilidade em sistemas urbanos de abastecimento de água e esgotamento sanitário. Revista Engenharia Sanitária e Ambiental, v. 9, n. 4, p. 269-279, 2004.

NASH, J. Non-cooperative games. Annals of Mathematics, v. 54, p. 286295, 1951.

ODUM, E.P. Fundamentals of ecology. 3. ed. Philadelphia: Saunders, 1971.

OLIVEIRA, S.V.W.B. Modelo para tomada de decisão na escolha de sistema de tratamento de esgoto sanitário. 2004. 293 f. Tese (Doutorado em Administração) - Faculdade de Economia, Administração e Contabilidade, Universidade de São Paulo, São Paulo, 2004.

OSBORNE, M.J. An introduction to game theory. New York: Oxford University Press, 2004.
RAGSDALE, C.T. Spreadsheet modeling \& decision analysis: a practical introduction to management science. 4. ed. Mason, Ohio: Thomson/ South-Western, 2004

SHIMIZU, T. Decisão nas organizações. 2. ed. São Paulo: Atlas, 2006.

SNIS - SISTEMA NACIONAL DE INFORMAÇÕES EM SANEAMENTO. Diagnóstico dos serviços de água e esgoto. Disponível em: <http:// www.snis.gov.br/>. Acesso em: 13 mar. 2007.

SOUZA, M.A.A. Um modelo para seleção de processos de tratamento de águas residuárias municipais. Associação Interamericana de Engenharia Sanitária e Ambiental - AIDIS. Gestão Ambiental no Século XXI. Lima, APIS, 1998, p.1-20.

VARIAN, H.R. Microeconomia: princípios básicos. 6. ed. Rio de Janeiro: Editora Campus, 2003.

VON SPERLING, M. Introdução à qualidade das águas e ao tratamento de esgoto. v. 1, 3. ed. Belo Horizonte: Departamento de Engenharia Sanitária e Ambiental - Universidade Federal de Minas Gerais, 2006. 